\title{
Erosividade mensal e anual da chuva no Estado de Minas Gerais
}

\author{
Carlos Rogério de Mello(1), Marcos Aurélio Carolino de Sá(2), Nilton Curi(3), José Marcio de Mello(4), \\ Marcelo Ribeiro Viola(1) e Antônio Marciano da Silva(1)
}

\begin{abstract}
(1)Universidade Federal de Lavras (Ufla), Dep. de Engenharia, Caixa Postal 3037, CEP 37200-000 Lavras, MG. E-mail: crmello@ufla.br, m.r.viola@hotmail.com, marciano@ufla.br (2)Embrapa Cerrados, BR 020, Km 18, CEP 73310-970 Planaltina, DF. E-mail: carolino@cpac.embrapa.br (3)Ufla, Dep. de Ciência do Solo. E-mail: niltcuri@ufla.br (4)Ufla, Dep. de Ciências Florestais. E-mail: jmmello@ufla.br
\end{abstract}

\begin{abstract}
Resumo - Este trabalho objetivou estimar e mapear a erosividade média $\left(\mathrm{EI}_{30}\right)$ mensal e anual, analisar a distribuição espacial da precipitação, durante o período chuvoso, e identificar zonas similares quanto a $\mathrm{EI}_{30}$ no Estado de Minas Gerais. Foram levantadas séries históricas de precipitação diária de 248 estações climatológicas para estimativa do coeficiente de chuva de Fournier $(\mathrm{Rc})$. Baseado na relação $\mathrm{EI}_{30} \mathrm{x} \mathrm{Rc}$, verificada em algumas localidades do Estado, o índice $\mathrm{EI}_{30}$ mensal foi estimado para as 248 estações. A geoestatística foi aplicada no mapeamento dos dados. O Estado de Minas Gerais pôde ser dividido em três zonas, com erosividade anual variando de 5.000 a $12.000 \mathrm{MJ} \mathrm{mm} \mathrm{ha}^{-1}$ ano $^{-1}$ : erosividade média-alta, nas regiões central, nordeste e parte da Zona da Mata; alta, no Triângulo Mineiro (extremo da região), e parte do nordeste e sul do Estado; e muito alta, na maior parte do Triângulo Mineiro, Alto Paranaíba, noroeste e leste. A erosividade não apresentou relação com a latitude e longitude e foi influenciada por efeitos orográficos e características climáticas de cada região.
\end{abstract}

Termos para indexação: erosão hídrica, mapeamento, geoestatística, $\mathrm{EI}_{30}$.

\section{Monthly and annual rainfall erosivity for Minas Gerais State}

\begin{abstract}
This work aimed to map monthly and annual rainfall erosivity $\left(\mathrm{EI}_{30}\right)$ mean, to analyze rainfall erosivity distribution, during rainfall season, and to identify rainfall erosivity zones in Minas Gerais State, Brazil. Daily pluviometric data from 248 weather stations dispersed in the State were used to determine the Fournier's rainfall coefficient $(\mathrm{Rc})$. Based on the relation $\mathrm{EI}_{30} \times \mathrm{Rc}$ obtained for some locations, $\mathrm{EI}_{30}$ was calculated for each weather station. Geostatistical tools were applied to map $\mathrm{EI}_{30}$ and pluviometric data. Minas Gerais comprises three zones with annual rainfall erosivity varying from 5,000 to $12,000 \mathrm{MJ} \mathrm{mm} \mathrm{ha}^{-1}$ year-1: medium-high erosivity, for central, northeastern and part of Zona da Mata; high, for Triângulo Mineiro (extreme of the region), and part of northeast and south of State; and very high, for most part of Triângulo Mineiro, Alto Paranaíba, northwest and east of State. Rainfall erosion behavior has not presented relation with latitude and longitude, and was influenced by orographic effect and weather characteristics of each region.
\end{abstract}

Index terms: water erosion, cartography, geostatistic, $\mathrm{EI}_{30}$.

\section{Introdução}

A erosão hídrica apresenta elevado potencial de redução na capacidade produtiva dos solos e pode comprometer os recursos hídricos superficiais.

Entre os diversos fatores ligados à erosão, a erosividade das chuvas é um dos mais importantes. A medida desta grandeza é realizada por índices, tais como o índice de erosividade padrão $\mathrm{EI}_{30}$ (Wischmeier \& Smith, 1978), relatado por diversos pesquisadores como uma medida satisfatória, devido à significativa correlação que esse índice apresenta com as perdas de solo (Silva et al., 1997, 2005).
A determinação da erosividade da chuva envolve um trabalho exaustivo de seleção e leitura de uma série de registros de chuvas. Esses dados são escassos e muitas vezes de difícil acesso. A fim de minimizar estes problemas, diversos autores correlacionaram o índice $\mathrm{EI}_{30}$ com o coeficiente de chuva (Rc), conhecido como índice de Fournier (Renard \& Freimund, 1994), o qual é facilmente obtido a partir do registro dos totais diários das precipitações. Tais dados estão disponíveis em maior número de localidades, o que simplifica sua obtenção, mas mantém precisão satisfatória na estimativa de $\mathrm{EI}_{30}$ (Mannaerts \& Gabriels, 2000; Silva, 2004). 
O Estado de Minas Gerais apresenta vasta abrangência territorial, e é cortado por extensas cadeias de montanhas. Massas de ar provenientes do extremo sul do continente e da região equatorial freqüentemente atingem o Estado. Sendo assim, Minas Gerais é afetado por precipitações de origem orográfica, precipitações de origem ciclônica, tanto frentes frias de origem polar (sistema atmosférico frontal), com chuvas de longa duração e de baixa a média intensidade, quanto frentes quentes e úmidas oriundas da região equatorial (Amazônia), que caracteriza um sistema atmosférico não frontal (Moreira, 1999, 2002; Vianello \& Alves, 2000). Durante o verão, também é comum a ocorrência do fenômeno conhecido como zonas de convergência do Atlântico Sul, gerado por zonas de baixa pressão atmosférica no Oceano Atlântico, com acúmulo de grande quantidade de nuvens. Este fenômeno, combinado com os sistemas ciclônicos, gera grandes volumes de precipitações (Moreira, 1999). Há de se mencionar ainda a ocorrência de precipitações convectivas, de alta intensidade e curta duração, porém, de pequeno alcance espacial, que produz eventos de chuva erosivos de magnitude considerável no Estado, especialmente nas regiões mais quentes e úmidas (Moreira, 2002).

Cada uma das situações acima pode predominar, com maior ou menor peso, nas regiões do Estado, devido às características climáticas e do relevo, entre outros fatores. Segundo Antunes (1986), o Estado apresenta, com base na classificação de Köppen, desde clima do tipo $\mathrm{Cwb}$, temperado com invernos frios e verões brandos, no Sul de Minas, até BSw, caracterizado como semiárido, no extremo norte e nordeste do Estado. Essas características resultam em grande variação na precipitação, o que acarreta possível variabilidade nos padrões de erosividade.

Dessa forma, a aplicação de técnicas que permitam o mapeamento de grandezas climáticas pode produzir resultados satisfatórios para o bom entendimento da distribuição dessa variável no espaço, conforme Mello et al. (2003) e Silva (2004). No entanto, algumas metodologias consideram apenas grandezas geométricas, como inverso de distância, desconsiderando a existência de dependência espacial. Esta situação pode produzir mapas enviesados que representam o fenômeno de forma menos precisa (Mello et al., 2003; Mello, 2004; Buytaert et al., 2006). As técnicas de interpolação geoestatísticas estão sendo amplamente aplicadas, mostrando melhor eficácia que as demais. Isto ocorre, principalmente, pelo controle de parcela do erro aleatório produzido pela influência espacial mútua entre as amostras, conhecida como dependência espacial, algo que a estatística clássica não considera (Vieira et al., 2002; Mello, 2004).

$\mathrm{O}$ objetivo deste trabalho foi estimar e mapear a erosividade média $\left(\mathrm{EI}_{30}\right)$ mensal e anual, analisar a distribuição espacial da precipitação, durante o período chuvoso, e identificar zonas similares quanto a $\mathrm{EI}_{30}$ no Estado de Minas Gerais.

\section{Material e Métodos}

Os dados utilizados neste estudo foram obtidos no Sistema de Informações Hidrológicas da Agência Nacional de Águas (ANA), constituindo-se de séries históricas pluviométricas, com duração mínima de dez anos, de 248 localidades (Figura 1) (Silva, 2004).

A erosividade mensal foi calculada, na forma do índice $\mathrm{EI}_{30}$, para o período de outubro a abril, que abrange todo o período chuvoso. Foram utilizadas equações que associam este índice e o índice de Fournier (Rc), e que, segundo Renard \& Freimund (1994), pode ser assim representado: $\mathrm{Rc}=\mathrm{p}^{2} / \mathrm{P}$; em que Rc é o coeficiente de chuva $(\mathrm{mm})$; p é a precipitação média mensal $(\mathrm{mm})$; e $\mathrm{P}$ é a precipitação média anual ( $\mathrm{mm})$.

No ajuste da relação entre $\mathrm{EI}_{30}$ e Rc, utilizou-se equações obtidas em Minas Gerais e em Estados vizinhos (Geominas, 2006). Assim, foram aplicadas as equações de Campinas, SP (Lombardi Neto \& Moldenhauer, 1992), Lavras, MG (Val, 1985) e Mococa, SP (Carvalho et al., 1989) na estimativa de $\mathrm{EI}_{30}$ para o Sul de Minas Gerais, com clima Cwa/Cwb; Nova Friburgo e Seropédica, RJ (Carvalho et al., 2005), para a Zona da Mata, com clima Cwa; Goiânia, GO (Silva et al., 1997), para o Triângulo Mineiro, com clima predominantemente Aw; uma equação geral do Leste de Minas Gerais desenvolvida por Oliveira (2006), para a região do Rio Doce, com clima Aw; Goiânia, GO, e Juazeiro, BA (Silva, 2004), para o noroeste de Minas, com clima Aw; Juazeiro, BA, e Sete Lagoas, MG (Marques et al., 1998), para a região do Vale do Jequitinhonha, com clima Aw/ BSw; e Lavras e Sete Lagoas, MG, para as regiões Campo das Vertentes e Alto São Francisco, com clima $\mathrm{Cwa} / \mathrm{Aw}$.

Depois do cálculo do índice $\mathrm{EI}_{30}$ mensal de cada uma das 248 localidades, foram utilizadas técnicas geoestatísticas para espacialização da erosividade e da precipitação, precedida pela análise exploratória dos dados. Desta maneira, foram estudados gráficos de ten- 
dências, averiguando a aplicabilidade das técnicas geoestatísticas, especialmente a hipótese intrínseca, e gráficos "box plot", para identificação de valores dis- crepantes, estatisticamente conhecidos como "outliers". A identificação e remoção de anisotropia foram realizadas conforme Vieira et al. (2002) e Mello (2004),

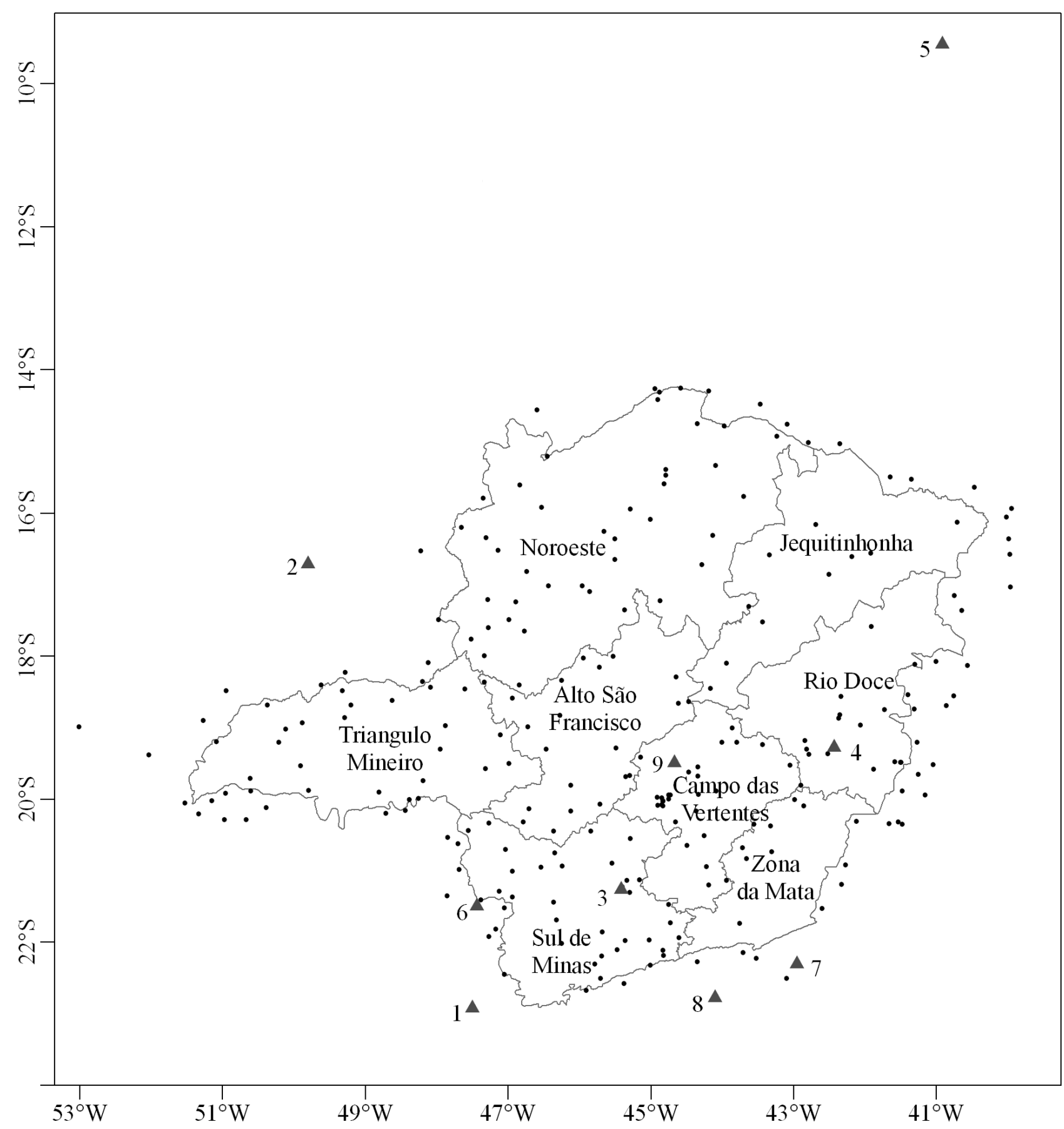

Figura 1. Locais em que foram determinadas as relações entre $\mathrm{EI}_{30}$ e $\mathrm{Rc}(\boldsymbol{\Delta})$ e localização das 248 estações pluviométricas utilizadas (•) (Geominas, 2006). 1, Campinas; 2, Goiânia; 3, Lavras; 4, Leste de Minas; 5, Juazeiro; 6, Mococa; 7, Nova Friburgo; 8, Seropédica; 9 , Sete Lagoas. 
plotando-se os semivariogramas experimentais nas direções $0,45,90$ e $135^{\circ}$, e avaliando seu comportamento em relação ao semivariograma isotrópico, não tendo sido obtida diferença significativa. As análises de continuidade espacial foram realizadas no Programa R, por meio do pacote GeoR (Ribeiro Junior \& Diggle, 2001).

Um ponto-chave da geoestatística consiste no ajuste do modelo teórico de semivariograma ao semivariograma experimental. Os modelos exponencial e esférico foram aplicados para a geração dos mapas de erosividade e precipitação no Estado de Minas Gerais. Estes modelos foram adotados após estudos preliminares realizados com o objetivo de se escolher o melhor modelo para cada uma das situações analisadas, o que foi conduzido com base no Grau de Dependência Espacial (GD) e validação cruzada. Esta última análise propicia estimativa do erro produzido pelo interpolador geoestatístico, conhecido como krigagem, quando se aplica determinado modelo de semivariograma (Vieira et al., 2002; Mello, 2004). O GD reflete a estrutura de continuidade espacial, pois é obtido pela relação entre o patamar e o patamar mais o efeito pepita do semivariograma. Quanto maior seu valor, maior a dependência espacial e mais eficiente será o mapeamento da variável pela krigagem. Neste estudo, a maioria dos modelos adotados, tanto para erosividade quanto para precipitação, gerou GD maior que $75 \%$, e foi considerada como de forte grau de dependência (Mello, 2004), o que demonstra que a aplicação da geoestatística é imprescindível em estudos desta natureza. Além disso, outros pesquisadores comprovaram o melhor desempenho destes modelos para o mapeamento de chuvas intensas (Mello et al., 2003; Buytaert et al., 2006; Viola, 2006) e precipitação pluvial mensal e anual, além da própria erosividade (Aquino, 2005).

Para fins de complemento da análise do comportamento da erosividade no Estado, além dos mapas de precipitação correspondentes aos períodos analisados, buscaram-se informações sobre o comportamento e distribuição espacial das chuvas intensas associadas a 30 min de duração no Estado (Figura 2). Além disso, foi analisada também a distribuição da erosividade anual de acordo com a latitude, longitude e precipitação anual, por meio de correlação estatística, aplicando-se o teste $\mathrm{t}$ de Student, a 5\% de probabilidade, com o intuito de se verificar, estatisticamente, tendências na distribuição geográfica da erosividade.

\section{Resultados e Discussão}

Na Figura 3 apresentam-se os mapas de erosividade média mensal no período chuvoso e erosividade anual, e na Figura 4, os mapas das precipitações médias correspondentes. Em outubro e abril, observa-se erosividade média mensal semelhante no Estado de Minas Gerais, variando de 100 a $600 \mathrm{MJ} \mathrm{mm} \mathrm{ha}^{-1} \mathrm{mês}^{-1}$. Ao se analisar o mês de novembro em comparação com outubro, a erosividade mensal praticamente dobra ou até triplica em alguns casos, com maior quantidade de chuvas.

No entanto, o aumento na erosividade em novembro ocorre de forma muito mais acentuada do que o aumento na precipitação, o que pode estar associado à maior concentração das chuvas neste mês. Marques et al. (1998), trabalhando com dados de Sete Lagoas, MG, verificaram, numa comparação entre os meses de dezembro e janeiro, um total precipitado $103 \%$ maior em dezembro, porém uma erosividade apenas $74 \%$ superior. Esses autores observaram, portanto, que em termos relativos, a erosividade foi maior no mês de janeiro, o que indica maior concentração das chuvas nesse mês.

Neste trabalho, em dezembro ocorreram os maiores valores mensais de erosividade, apesar de o total precipitado ter sido bastante semelhante a janeiro. Verificase, no mapa de erosividade, valores em torno de $3.000 \mathrm{MJ} \mathrm{mm} \mathrm{ha}^{-1} \mathrm{mês}^{-1} \mathrm{em}$ dezembro, ao passo que em janeiro, o valor máximo permaneceu em torno de

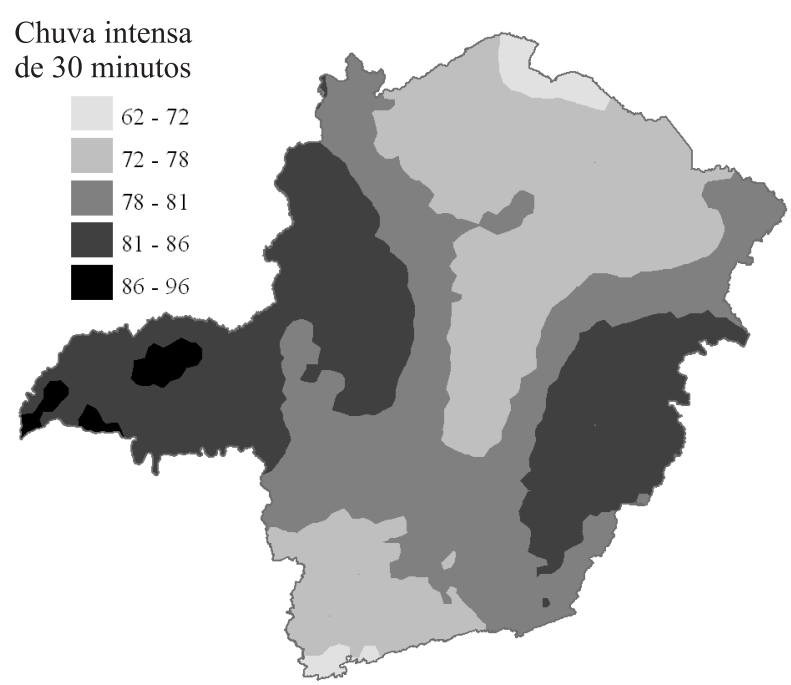

Figura 2. Distribuição de chuvas intensas com 30 minutos de duração, em milímetros por hora, no Estado de Minas Gerais (Viola, 2006). 

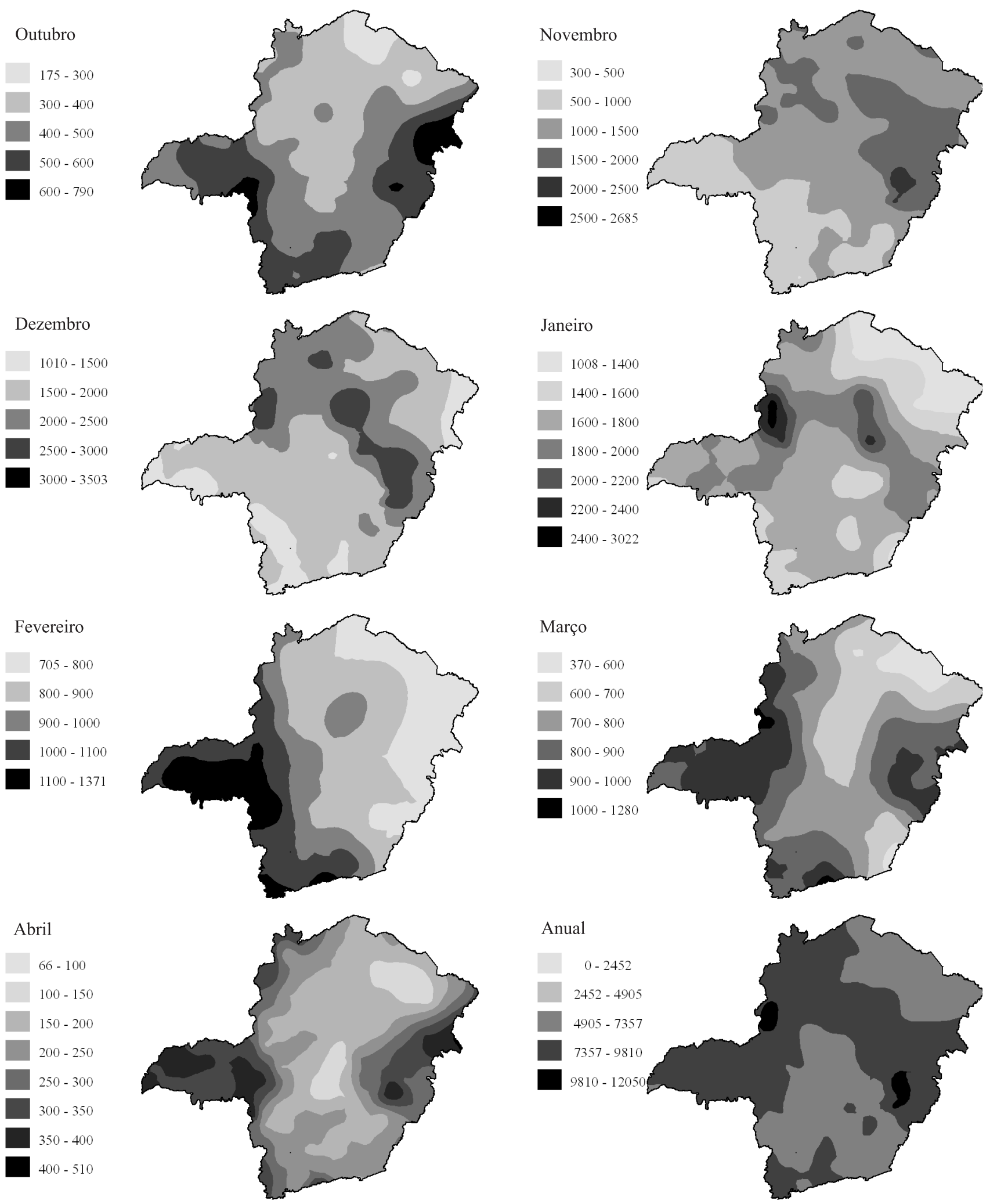

Figura 3. Mapas de erosividade mensal $\left(\mathrm{MJ} m \mathrm{mma}^{-1} \mathrm{mê}^{-1}\right)$ e erosividade anual ( $\left.\mathrm{MJ} \mathrm{mm} \mathrm{ha}^{-1} \mathrm{ano}^{-1}\right)$ do Estado de Minas Gerais. 


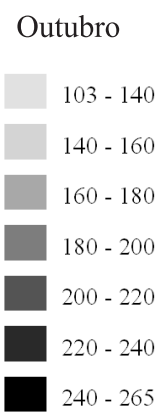

Dezembro
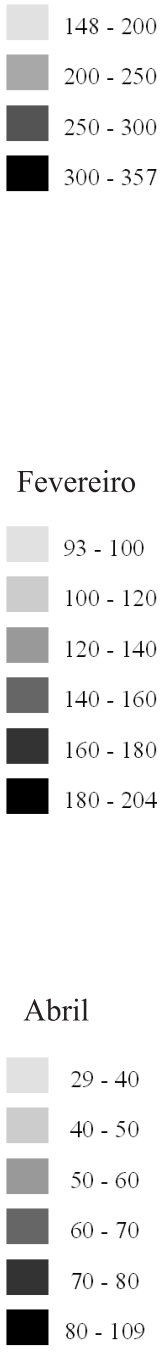
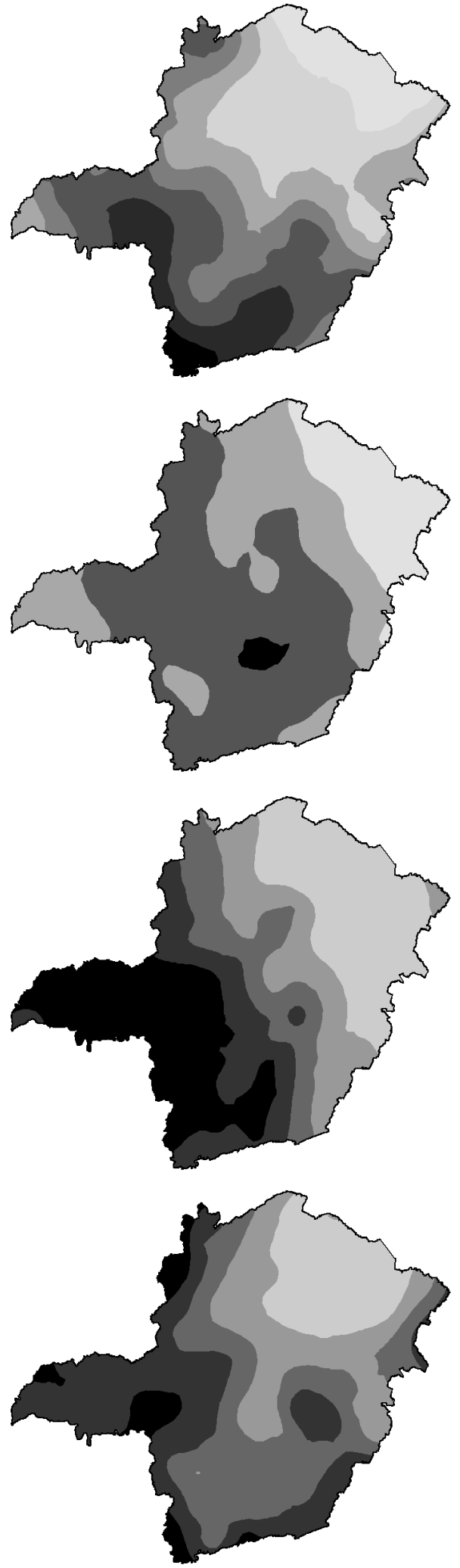

Janeiro

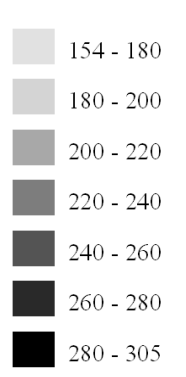

Março

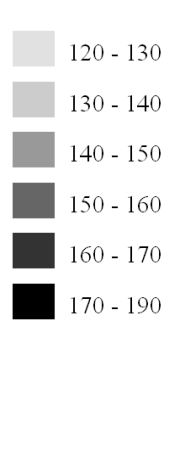

Anual
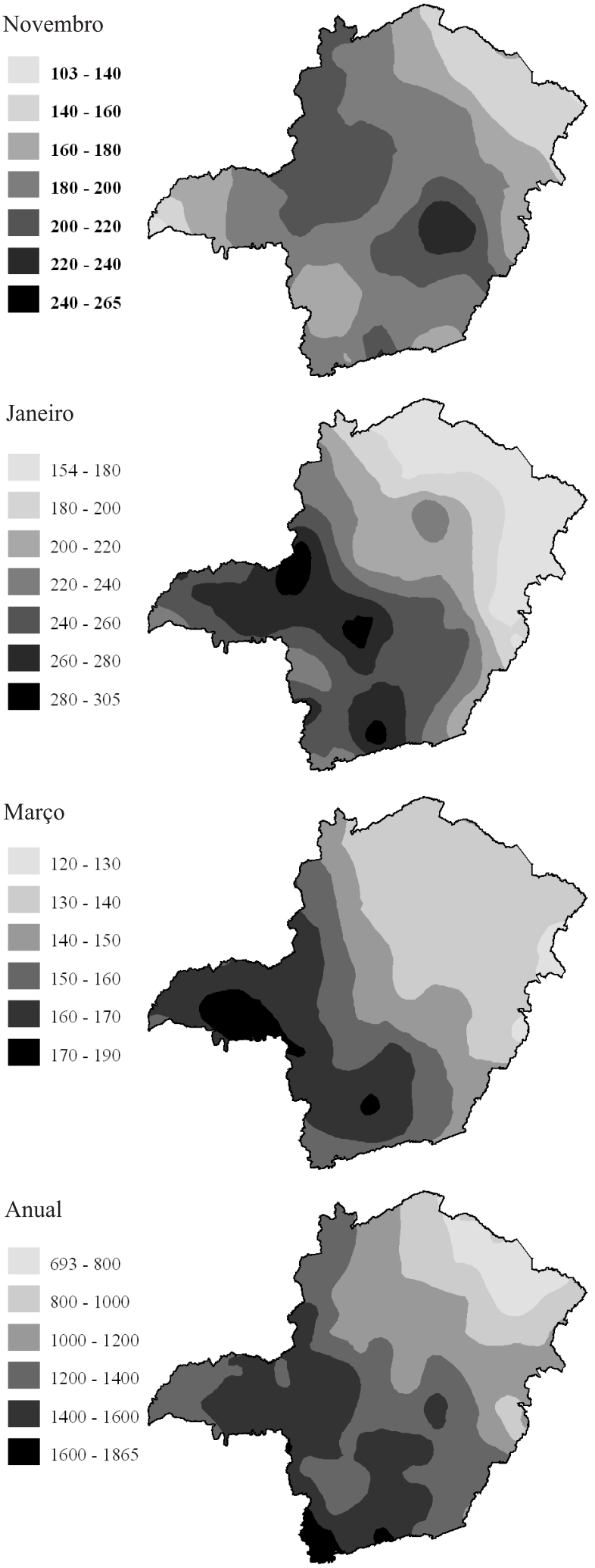

Figura 4. Mapas de precipitações mensais (mm) e precipitação anual (mm) do Estado de Minas Gerais. 
$2.500 \mathrm{MJ} \mathrm{mm} \mathrm{ha}^{-1}$ por mês. Em fevereiro, foi possível observar redução expressiva da erosividade em relação a janeiro e dezembro, mas semelhante ao mês de março.

Nos meses de maior concentração das chuvas, novembro a janeiro, observou-se distribuição espacial muito semelhante da erosividade, com valores mais altos para uma faixa que corta o Estado de leste a noroeste. A distribuição das chuvas mostra valores mensais para o leste (Rio Doce), sul, Triângulo e noroeste consideravelmente mais elevados e, na região sul, esta situação não implicou em áreas com maiores erosividades, sendo reflexo de uma melhor distribuição da chuva ao longo do período chuvoso.

A erosividade anual média em Minas Gerais variou de 5.000 a mais de $12.000 \mathrm{MJ} \mathrm{mm} \mathrm{ha}^{-1} \mathrm{ano}^{-1}$, com total anual de precipitação oscilando entre 800 e $1.700 \mathrm{~mm}$. Quanto à distribuição espacial da erosividade anual, verificou-se que as regiões do Triângulo Mineiro, Alto Paranaíba, adentrando para o noroeste do Estado, bem como a região do Vale do Rio Doce, registraram os maiores valores de erosividade anual média, em alguns casos, superiores a $10.000 \mathrm{MJ} \mathrm{mm} \mathrm{ha}^{-1} \mathrm{ano}^{-1}$.

Pelo mapa de precipitação total anual média, observou-se que as regiões do Triângulo Mineiro e Alto Paranaíba apresentaram os valores mais elevados, assim como a região próxima da Serra da Mantiqueira (Sul de Minas), com totais superiores a $1.500 \mathrm{~mm}$. No entanto, na região leste, o total precipitado anualmente é inferior a $1.200 \mathrm{~mm}$. Esta particularidade enfatiza que maior quantidade anual de precipitação não necessariamente implica maior erosividade anual, e o Sul de Minas Gerais é o melhor exemplo dessa situação, onde ocorre total anual de chuvas consideravelmente superior ao do leste, mas sem os mesmos níveis de erosividade. Este aspecto está associado a maior concentração das chuvas na região leste, com um período chuvoso mais curto que no Sul de Minas, uma vez que esta última região apresenta clima mais ameno $(\mathrm{Cwb} / \mathrm{Cwa})$ e mais influenciado por sistemas atmosféricos do tipo frontal (Moreira, 2002).

Dessa forma, verifica-se que maior quantidade de chuva anual não necessariamente produzirá maior $\mathrm{EI}_{30}$, já que esse índice está associado a maior concentração das chuvas, decorrente das características climáticas, bem como da dinâmica e da influência de fatores associados à circulação atmosférica. Silva (2004) concluiu que a erosividade anual é altamente dependente do total precipitado, tendo encontrado coeficiente de determinação de $0,97^{*}$ entre essas grandezas, mapeando a erosividade no Brasil.
Os resultados obtidos não estão de acordo com esta análise, pois, além da distribuição espacial da erosividade não ter apresentado dependência do total precipitado, foi encontrado coeficiente de correlação de apenas $0,155^{\text {ns }}$ entre esse valores (Figura 5). No trabalho de
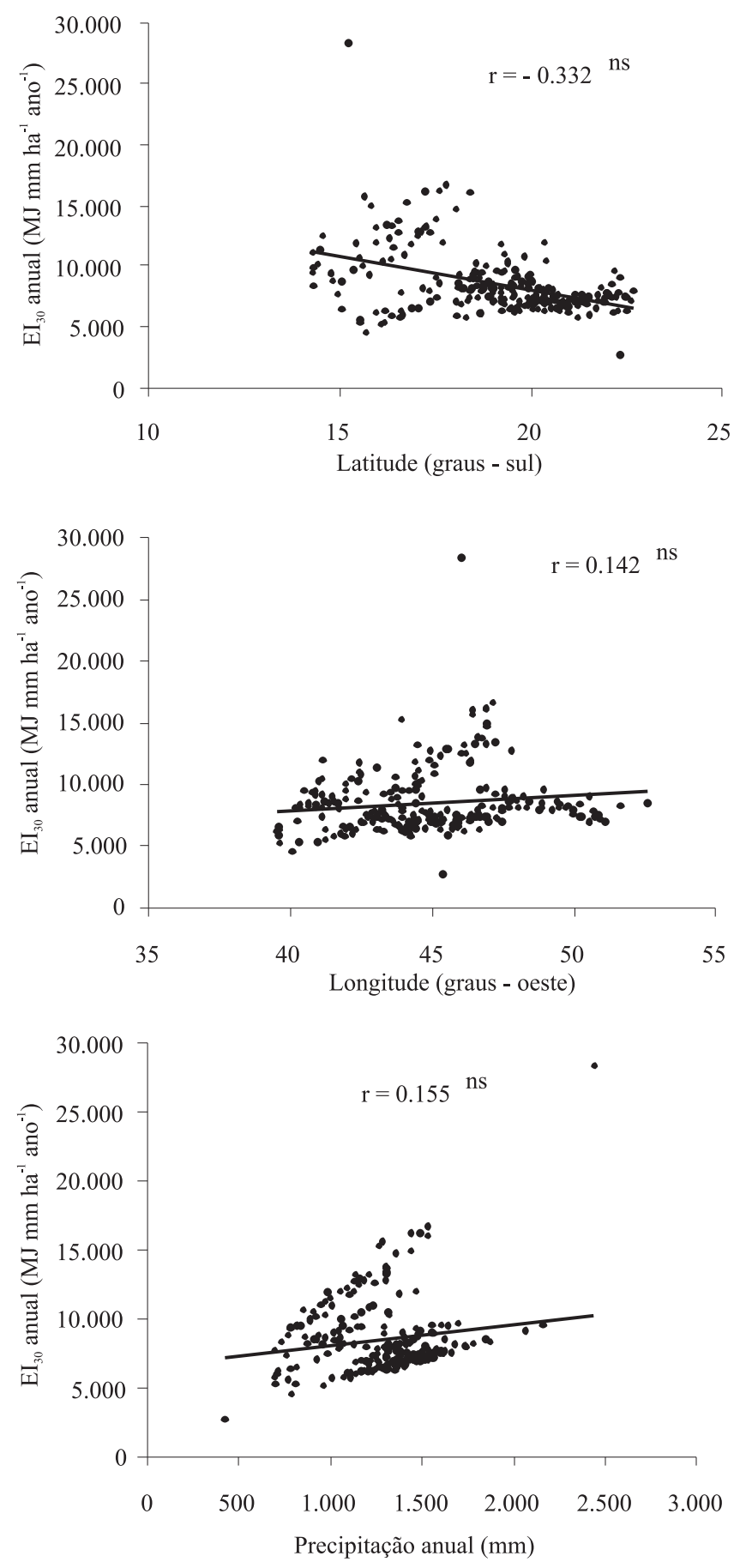

Figura 5. Correlação entre erosividade anual $\left(\mathrm{EI}_{30}\right)$ e latitude (a), longitude (b), e precipitação anual (c), no Estado de Minas Gerais. 
Silva (2004), foi aplicada apenas uma equação do tipo $\mathrm{EI}_{30} \times \mathrm{Rc}$ para representar cada uma das grandes regiões brasileiras e estas apresentam grandes diferenças climáticas, até mesmo dentro de um mesmo Estado. Esta situação pode conduzir a resultados que não reflitam totalmente a realidade física do fenômeno da erosividade e sua relação com as características climáticas e orográficas.

A região leste, o Triângulo Mineiro e o Alto Paranaíba apresentam os maiores valores de chuvas intensas, com duração de 30 minutos, sendo uma das explicações da distribuição espacial encontrada. É possível explicar esse comportamento baseado nos efeitos orográfico e de convecção atmosférica, sendo esse último gerado por maiores temperaturas médias, características do clima Aw, típico de ambas as regiões (Antunes, 1986). Além desse aspecto, é importante mencionar fenômenos de circulação atmosférica, como as zonas de convergência do Atlântico Sul, que atuam no Sudeste do Brasil no verão, normalmente combinadas com sistemas atmosféricos ciclônicos (Moreira, 1999).

Com base na classificação de Foster et al. (1981), é possível caracterizar e dividir o Estado de Minas Gerais em regiões específicas quanto ao comportamento anual da erosividade. A subdivisão do Estado tem por objetivo fornecer subsídios para melhor planejamento do controle da erosão hídrica, haja vista que muitas regiões, com atividade agrícola intensa, encontram-se em locais naturalmente caracterizados como tendo chuvas altamente erosivas, como Triângulo Mineiro e Alto Paranaíba. Assim, pode-se zonear a erosividade anual em Minas Gerais da seguinte forma: erosividade média a alta regiões central, parte da Zona da Mata mineira e Sul de Minas, além do nordeste de Minas Gerais, com valores entre 4.905 e $7.357 \mathrm{MJ} \mathrm{mm} \mathrm{ha}^{-1}$ ano $^{-1}$; erosividade alta - Triângulo Mineiro e noroeste do Estado, partes do centro-norte de Minas e do Sul de Minas Gerais, com valores entre 7.357 e $9.810 \mathrm{MJ} \mathrm{mm} \mathrm{ha}{ }^{-1}$ ano $^{-1}$; erosividade muito alta - parte do Alto Paranaíba, leste e região do entorno da Serra da Mantiqueira, com valores acima de $9.810 \mathrm{MJ} \mathrm{mm} \mathrm{ha}^{-1} \mathrm{ano}^{-1}$.

A análise de correlação entre erosividade e coordenadas geográficas, apresentada na Figura 5, mostra que não há um comportamento diferencial da erosividade decorrente da latitude e ou longitude, evidenciado por coeficientes de correlação não-significativos. No trabalho de Silva (2004), foi verificada influência da longitude no comportamento da erosividade no Brasil, basicamente pela influência da Região Amazônica em relação ao Nordeste do país. Em Minas Gerais, o fator orográfico e as características climáticas são mais rele- vantes para o comportamento da erosividade. Esse resultado também demonstra a influência do clima e da concentração das chuvas em determinadas regiões, uma vez que se esperava um gradiente positivo de $\mathrm{EI}_{30}$ entre o norte e o sul do Estado. Este comportamento não ocorreu de forma contínua, já que, sob latitudes médias do Estado (Vale do Rio Doce e Alto Paranaíba), verificouse erosividade maior que em latitudes maiores (ao Sul), propiciando correlação negativa. Em termos longitudinais, o coeficiente é ainda menor, mostrando total independência da erosividade anual na direção leste-oeste.

\section{Conclusões}

1. O Estado de Minas Gerais apresenta valores de erosividade elevados, e pode ser dividido em três zonas de erosividade semelhante: média a alta; alta; e muito alta.

2. Existe uma relação de independência entre a distribuição da erosividade e das chuvas no Estado de Minas Gerais.

3. A erosividade anual, no Estado, não é influenciada pelas coordenadas geográficas.

4. O efeito orográfico e as características climáticas específicas de cada região determinam o comportamento espacial da erosividade em Minas Gerais.

\section{Referências}

ANTUNES, F.Z. Caracterização climática do estado de Minas Gerais: climatologia agrícola. Informe Agropecuário, v.12, p.9-13, 1986.

AQUINO, R.F. Padrões de chuva e variabilidade da erosividade para o Sul de Minas Gerais. 2005. 95p. Dissertação (Mestrado) Universidade Federal de Lavras, Lavras.

BUYTAERT, W.; CELLERI, R.; WILLEMS, P.; BIÈVRE, B. de; WYSEURE, G. Spatial and temporal rainfall variability in mountainous areas: a case study from the South Ecuadorian Andes. Journal of Hydrology, v.329, p.413-421, 2006.

CARVALHO, D.F. de; MONTEBELLER, C.A.; FRANCO, E.M.; VALCARCEL, R.; BERTOL, I. Padrões de precipitação e índices de erosividade para as chuvas de Seropédica e Nova Friburgo, RJ. Revista Brasileira de Engenharia Agrícola e Ambiental, v.9, p.7-14, 2005.

CARVALHO, M.P.; LOMBARDI NETO, F.; VASQUES FILHO, J.; CATANEO, A. Erosividade da chuva de Mococa (SP) analisada pelo índice $\mathrm{EI}_{30}$. Revista Brasileira de Ciência do Solo, v.13, p.243-249, 1989.

FOSTER, G.R.; McCOOL, D.K.; RENARD, K.G.; MOLDENHAUER, W.C. Conversion of the universal soil loss equation to SI metric units. Journal Soil Water Conservation, v.36, p.355-359, 1981. 
GEOMINAS. Atlas de zoneamento agroclimático do Estado de Minas Gerais. Disponível em: <http://www.geominas.mg.gov.br> Acesso em: 1ํjul. 2006.

LOMBARDI NETO, F.; MOLDENHAUER, W.C. Erosividade da chuva: sua distribuição e relação com perdas de solo em Campinas, SP. Bragantia, v.51, p.189-196, 1992.

MANNAERTS, C.M.; GABRIELS, D. Rainfall erosivity in Cape Verde. Soil and Tillage Research, v.55, p.207-212, 2000.

MARQUES, J.J.G. de S. e M.; ALVARENGA, R.C.; CURI, N. Erosividade das chuvas da região de Sete Lagoas, MG. Pesquisa Agropecuária Brasileira, v.33, p.761-768, 1998.

MELLO, C.R. de; LIMA, J.M.; SILVA, A.M.; MELLO, J.M.; OLIVEIRA, M.S. Krigagem e inverso do quadrado da distância para interpolação dos parâmetros da equação de chuvas intensas. Revista Brasileira de Ciência do Solo, v.27, p.925-933, 2003.

MELLO, J.M. de. Geoestatística aplicada ao inventário florestal. 2004. 110p. Tese (Doutorado) - Escola Superior de Agricultura Luiz de Queiroz, Piracicaba.

MOREIRA, A.A.M. A influência da circulação de macro-escala sobre o clima de Belo Horizonte: estudo sobre as possíveis influências do fenômeno El Niño sobre o clima local. 1999. 186p. Dissertação (Mestrado) - Universidade Federal de Minas Gerais, Belo Horizonte.

MOREIRA, J.L.B. Estudo da distribuição espacial das chuvas em Belo Horizonte e em seu entorno. 2002. 186p. Dissertação (Mestrado) - Universidade Federal de Minas Gerais, Belo Horizonte. OLIVEIRA, F.P. Erosão hídrica em áreas florestais no Vale do Rio Doce, região Centro-Leste do Estado de Minas Gerais. 2006. 105p. Dissertação (Mestrado) - Universidade Federal de Lavras, Lavras.

RENARD, K.G; FREIMUND, J.R. Using monthly precipitation data to estimate the R-factor in the revised USLE. Journal of Hydrology, v.157, p.287-306, 1994.
RIBEIRO JUNIOR, P.J.; DIGGLE, P.J. GeoR: a package for geoestatistical analysis. R-News, v.1, p.15-18, 2001. Disponível em: <http://cran.r-project.org/doc/Rnews>. Acesso em: 8 mar. 2007.

SILVA, A.M. da. Rainfall erosivity map for Brazil. Catena, v.57, p.251-259, 2004.

SILVA, A.M. da; SILVA, M.L.N.; CURI, N.; LIMA, J.M. de; AVANZI, J.C.; FERREIRA, M.M. Perdas de solo, água, nutrientes e carbono orgânico em Cambissolo e Latossolo sob chuva natural. Pesquisa Agropecuária Brasileira, v.40, p.1223-1230, 2005.

SILVA, M.L.N.; FREITAS, P.L.; BLANCANEUAX, P.; CURI, N.; LIMA, J.M. Relação entre parâmetros da chuva e perdas de solo e determinação da erodibilidade de um Latossolo Vermelho-Escuro em Goiânia (GO). Revista Brasileira de Ciência do Solo, v.21, p.131137, 1997.

VAL, L.A. Avaliação dos índices de erosividade das chuvas no Município de Lavras, MG. 1985. 72p. Dissertação (Mestrado) Universidade Federal de Lavras, Lavras.

VIANELLO, R.L.; ALVES, A.R. Meteorologia básica e aplicações. Viçosa: UFV, 2000. 448p.

VIEIRA, S.R.; MILLETE, J.; TOPP, G.C.; REYNOLDS, W.D. Handbook for geostatistical analysis of variability in soil and climate data. In: ALVAREZ VENEGAS, V.H.; SCHAEFER, C.E.G.R.; BARROS, N.F.; MELLO, J.W.V.; COSTA, L.M. (Ed.). Tópicos em ciência do solo. Viçosa: Sociedade Brasileira de Ciência do Solo, 2002. v.2, p.1-46.

VIOLA, M.R. Comportamento espacial e temporal de chuvas intensas no Estado de Minas Gerais. 2006. 74p. Monografia (Graduação) - Universidade Federal de Lavras, Lavras.

WISCHMEIER, W.H.; SMITH, D.D. Predicting rainfall erosion losses: a guide to conservation planning. Washington: USDA, 1978. $58 \mathrm{p}$.

Recebido em 17 de outubro de 2006 e aprovado em 28 de fevereiro de 2007 